\title{
Different Projections of the Central Amygdaloid Nucleus Mediate Autonomic and Behavioral Correlates of Conditioned Fear
}

\author{
Joseph E. LeDoux, Jiro Iwata, Piera Cicchetti, and Donald J. Reis \\ Division of Neurobiology, Cornell University Medical College, New York, New York 10021
}

\begin{abstract}
The purpose of the present study was to determine whether lesions of areas projected to by the central amygdaloid nucleus (ACE) would disrupt the classical conditioning of autonomic and/or behavioral emotional responses. The areas studied included 3 projection targets of the ACE: the lateral hypothalamic area (LH), midbrain central gray (CG) region, and bed nucleus of the stria terminalis (BNST). Lesions were made either electrolytically or by microinjection of ibotenic acid, which destroys local neurons without interrupting fibers of passage. Two weeks later, the animals were classically conditioned by pairing an acoustic stimulus with footshock. The next day, conditioned changes in autonomic activity (increases in arterial pressure) and emotional behavior ("freezing," or the arrest of somatomotor activity) evoked by the acoustic conditioned stimulus (CS) were measured during extinction trials. Electrolytic and ibotenic acid lesions of the LH interfered with the conditioned arterial pressure response, but did not affect conditioned freezing. Electrolytic lesions of the rostral CG disrupted conditioned freezing but not conditioned changes in arterial pressure. Ibotenic acid injected into the rostral CG reduced neither the arterial pressure nor the freezing response. Injection of ibotenic acid in the caudal CG, like electrolytic lesions of the rostral CG, disrupted the freezing, but not the arterial pressure response. Injection of ibotenic acid into the BNST had no effect on either response. These data demonstrate that neurons in the $\mathrm{LH}$ are involved in the autonomic, but not the behavioral, conditioned response pathway, whereas neurons in the caudal CG are involved in the behavioral, but not the autonomic, pathway. Different efferent projections of the central amygdala thus appear to mediate the behavioral and autonomic concomitants of conditioned fear.
\end{abstract}

The central circuitry mediating the classical conditioning of fear to an acoustic stimulus in rats involves transmission through primary auditory structures of the brain stem to the auditory receptive region of the thalamus and, from there, directly to the amygdala (LeDoux et al., 1984-1986a, b; LeDoux, 1986, 1987;

\footnotetext{
Received Aug. 13, 1987; revised Nov. 19, 1987; accepted Nov. 27, 1987.

This work was supported by research grants from the National Institute of Mental Health (MH\# 38774), the National Institute of Health (HL 18974), and The American Heart Association (GIA 84-836). J.E.L. is an Established Investigator of The American Heart Association (EI 86-181) and is the recipient of an NIMH Merit award.

Correspondence should be addressed to Dr. J. E. LeDoux, Laboratory of Neurobiology, Cornell University Medical College, 411 East 69th Street, New York, NY 10021.

Copyright (C) 1988 Society for Neuroscience $0270-6474 / 88 / 072517-13 \$ 02.00 / 0$
}

Iwata et al., 1986a). The critical amygdaloid regions are located in the dorsal part of this structure, and include the lateral and central nuclei and the amygdalostriatal transition zone (Iwata et al., 1986a; LeDoux et al., 1986a). Since the major projection from the acoustic thalamus terminates in the lateral nucleus and the amygdalostriatal zone (LeDoux et al., 1985), one of these regions probably serves as the sensory interface of the amygdala during conditioning (Cicchetti et al., 1987). In contrast, the amygdaloid output pathway is likely to involve the central nucleus, a structure implicated in the expression of the autonomic and behavioral correlates of emotional arousal by lesion (Kapp et al., 1979; Gentile et al., 1986; Hitchcock and Davis, 1986; Iwata et al., 1986a), electrical stimulation (Ursin and Kaada, 1960; Hilton and Zbrozyna, 1963; Reis and Oliphant, 1964; Heinemann et al., 1973; Kapp et al., 1982; Galeno and Brody, 1983; Iwata et al., 1987), and unit recording (Applegate et al., 1982; Pascoe and Kapp, 1985a, b) studies in several species.

If the central amygdaloid nucleus (ACE) is an essential link in the pathway mediating the autonomic and behavioral correlates of conditioned fear, it should be possible to disrupt conditioned fear responses by destroying areas to which the central nucleus projects. Studies over the past several years have provided detailed descriptions of the efferent targets of the central nucleus in a number of mammalian species (Hopkins and Holstedge, 1978; Krettek and Price, 1978a, b; Saper, 1979; Price, 1981; Price and Amaral, 1981; Schwaber et al., 1982; van der Kooy et al., 1984; Cassell et al., 1986). In the present study we have examined the effects of damage to 3 of the areas purported to receive efferents from the central amygdala, including the bed nucleus of the stria terminalis (BNST), the lateral hypothalamic area (LH), and the midbrain central gray (CG) region. Our objectives were to determine whether such lesions would reproduce the disruptive effects of amygdala damage on fear conditioning, to determine whether the disruption of fear conditioning produced by these lesions is due to the destruction of neurons intrinsic to the lesioned area or to damage to fibers of passage, and to determine whether autonomic and behavioral conditioned fear responses might be separately disrupted by lesions of different projection targets. A short report on some of these findings has been published (Iwata et al., 1986b).

\section{Materials and Methods}

Animals

Studies were conducted using male Sprague-Dawley rats weighing 300 $350 \mathrm{gm}$. The animals were individually housed in clear plastic cages with free access to water and laboratory chow. The housing area was thermally controlled, sealed to sunlight, and maintained on a fluorescent 
light cycle (on at 0700 , off at 1900). All behavioral and surgical procedures were performed during the light phase of the cycle.

\section{Placement of brain lesions}

Projection targets of the central nucleus of the amygdala were destroyed electrolytically and/or by microinjection of ibotenic acid. For electrolytic lesions, the rats were anesthetized with halothane $(2.5 \%$ in $100 \%$ oxygen) and placed in a stereotaxic frame. The cranium was exposed and a small burr hole was made using a dental drill. A monopolar stainless steel electrode ( $200 \mu \mathrm{m}$ diameter), insulated with epoxy to within $200 \mu \mathrm{m}$ of the tip, was lowered through an incision in the dura to the target region. Lesions were made by passing anodal constant current (1.0 mA, 10-15 sec; Grass DC Lesion Maker) through the electrode. The cathode was connected to the open wound.

In some brain areas, ibotenic acid (IBO; Sigma Chemical Co.) was used to selectively destroy neuronal cell bodies while sparing axons of passage (Coyle and Schwarcz, 1983). Rats were prepared for stereotaxic surgery, as described above. IBO $(10 \mu \mathrm{g} / \mu 1,0.2-0.3 \mu \mathrm{l})$ dissolved in phosphate buffer $(0.1 \mathrm{M}, \mathrm{pH} 7.4)$ was loaded into a glass micropipette using negative pressure. The pipette was lowered to the target area and the solution was slowly $(0.1 \mu \mathrm{l} / \mathrm{min})$ infused using a pressure-driven microinjection device (Amaral and Price, 1984). Following completion of the injection, the pipette was left in place for at least $10 \mathrm{~min}$. Subsequently, the pipette was slowly removed from the brain.

The areas lesioned included 3 projection targets of ACE (Krettek and Price, 1978a; Price, 1981): BNST, LH, and CG. All lesions were bilateral and lesion placement was guided using stereotaxic coordinates from an atlas of the rat brain (Paxinos and Watson, 1982). The anterior-posterior (AP), medial-lateral (ML), and dorsal-ventral (DV) coordinates were computed relative to the interaural line.

Lesions of LH (AP, 6.2; ML, 1.5; DV, 1.0) were made both electrolytically and with IBO. CG lesions were located in either the rostral (AP, 2.5; ML, 0.5; DV, 4.0) or caudal (AP, 1.0; ML, 0.5; DV, 4.0) part of this structure. Rostrally, both electrolytic and IBO lesions were made, whereas caudal CG lesions were only made by microinjection of IBO. BNST (AP, 8.5; ML, 1.5, DV , 2.5) lesions were made by microinjection of IBO.

Following completion of surgical procedures, the wound was closed, the anesthesia discontinued, and the animal was placed in its home cage. After recovery from anesthesia under a heat lamp, the animal was returned to the housing area. Body weight and food and water intake were monitored routinely.

\section{Chronic catheterization for cardiovascular recording in freely behaving rats}

$\Lambda$ fter at least $12 \mathrm{~d}$ of recovery from brain surgery, a catheter was implanted for recording systemic arterial pressure. Procedures for implantation and maintenance of catheters have been described (Snyder et al., 1978; LeDoux et al., 1982). In brief, the animals were anesthetized with halothane ( $2.5 \%$ in $100 \%$ oxygen). A plastic (Tygon) cannula (0.012 in. I.D.) filled with saline $(0.9 \%)$-containing heparin $(100 \mathrm{U} / \mathrm{ml})$ was inserted into the thoracic aorta via the left common carotid artery and its tip placed at the level of the diaphragm. With the cannula fixed to the soft tissues with sutures, the free end was passed subcutaneously behind the ear to the back of the neck, brought through a stab wound in the skin, and sealed with a stainless steel obturator. The neck wound was sutured and the rat returned to its home cage. The cannula was flushed daily with $0.5 \mathrm{ml}$ of heparinized saline.

\section{Behavioral methods}

Classical conditioning. On the day following cannulation, the rats were removed from their home cage, placed individually in a standard rodentconditioning chamber enclosed by a sound-attenuating cubicle (Coulbourn Instruments, Lehigh Valley, PA), and subjected to classical conditioning. The conditioned stimulus (CS) was a pure tone of $800 \mathrm{~Hz}$ produced by a frequency generator, amplified to $80 \mathrm{~dB}$, and presented for $10 \mathrm{sec}$ through a speaker mounted on the front panel of the conditioning chamber. The unconditioned stimulus (US) consisted of a brief $(0.5 \mathrm{sec})$ delivery of current $(2.2 \mathrm{~mA})$, which was distributed across the grid floor of the conditioning chamber.

Stimulus presentation was controlled by a microprocessor (Apple II). For the first 10 trials, the CS was presented alone. For the subsequent 30 trials, the final $0.5 \mathrm{sec}$ of the CS was coextensive with the US. The intertrial interval was $150 \mathrm{sec}$ on the average (range, 100-200 sec).
Following the training session, which lasted $103 \mathrm{~min}$, the animal was returned to its home cage and transferred to the housing area.

Assessment of conditioned responses. All tests involved presentation of the CS during extinction trials (no US) conducted in the animal's home cage on the day after conditioning. This procedure, used in previous studies (LeDoux et al., 1984, 1986a, b; Iwata et al., 1986a, b), allows the measurement of cardiovascular responses during a quiescent state and provides a relatively pure assessment of the responses elicited by the CS, independent of contextual cues associated with the conditioning apparatus.

$\Lambda t$ the time of the cardiovascular test, the home cage was placed inside of a sound-attenuating test box and the arterial cannula was connected to a strain-gauge transducer (Statham P23Db), which rested outside the box at the level of the animal's heart. Pulsatile and mean arterial pressure were continuously recorded from the transducer via interlocked input couplers (Beckman 9872; 9806) of a chart recorder (Beckman Dynagraph Type R611). All data were simultaneously recorded on-line by a microcomputer (LSI 11/23; Digital Equipment), which sampled arterial pressure at $100 \mathrm{~Hz}$. Incoming data were digitized, processed, and stored on disk for subsequent analysis and display.

After the cannula was connected, about $10 \mathrm{~min}$ were allowed for the animal to acclimate to the test box. The CS was then presented to the resting animal 3 times through a speaker located inside the test box directly above the home cage. Stimulus presentation was controlled by the LSI 11/23 microcomputer. The stimulus parameters and schedule of presentation were the same as during conditioning. However, if the animal moved during the prestimulus baseline, the trial was aborted and immediately rescheduled. Arterial pressure was recorded continuously by the computer during each second of the $10 \mathrm{sec}$ stimulus and for the $10 \mathrm{sec}$ preceding and following the stimuli. Following the 3 trials, the home cage was returned to the housing area.

Approximately $2 \mathrm{hr}$ after completion of the cardiovascular test, freezing during the $\mathrm{CS}$ was measured. The home cage was brought into the behavioral laboratory. A new home cage with clean bedding was put in the test box and the rat was transferred to it. This procedure elicits a high level of exploratory activity (Bouton and Bolles, 1980; I eDoux et al., 1984). After about $15 \mathrm{sec}$ of continuous movement, the CS was presented through the overhead speaker for $120 \mathrm{sec}$. The amount of time accounted for by freezing was measured (Bouton and Bolles, 1980; LeDoux et al., 1984).

Unconditioned responses. Unconditioned arterial pressure responses evoked by the footshock stimulus were measured about $1 \mathrm{hr}$ after completion of the freezing test. The rat was placed in the conditioning chamber and the arterial cannula was connected to the transducer. After basal cardiovascular activity stabilized, the footshock $(2.2 \mathrm{~mA}, 0.5 \mathrm{sec})$ was delivered. Mean arterial pressure was recorded by the computer, as described above, for the $10 \mathrm{sec}$ preceding and following the stimulus.

\section{Histological evaluation of lesion placement}

Following completion of the behavioral studies, the animals were given an overdose of sodium pentobarbital and perfused with normal saline and $10 \%$ buffered formalin through the left ventricle of the heart. The brains were frozen and sectioned at $40 \mu \mathrm{m}$, and every fourth section was saved and stained with thionin. The location of the lesions was plotted using an overhead projector.

\section{Results}

\section{Lateral hypothalamic area lesions}

The lateral hypothalamic area was lesioned both electrolytically $(n=8)$ and with IBO $(n=16)$. Controls were either shamoperated $(n=5)$ or vehicle-injected $(n=8)$. Body weight decreased in the electrolytic lesion group during recovery $(-45 \pm$ $15 \mathrm{gm})$. However, the IBO $(26 \pm 6 \mathrm{gm})$ and control $(50 \pm 3$ $\mathrm{gm})$ groups gained weight.

Histological analysis of lesion location demonstrated that each animal in the electrolytic lesion group sustained damage to the LH area. The lesions were usually confined by the internal capsule laterally, the medial lemniscus dorsally, the fornix medially, and the surface of the brain ventrally (Fig. 1). IBO lesions were located in the same general area as the electrolytic lesions (Fig. 1). Extensive cell loss occurred in the LH area (Fig. 2). Two of 

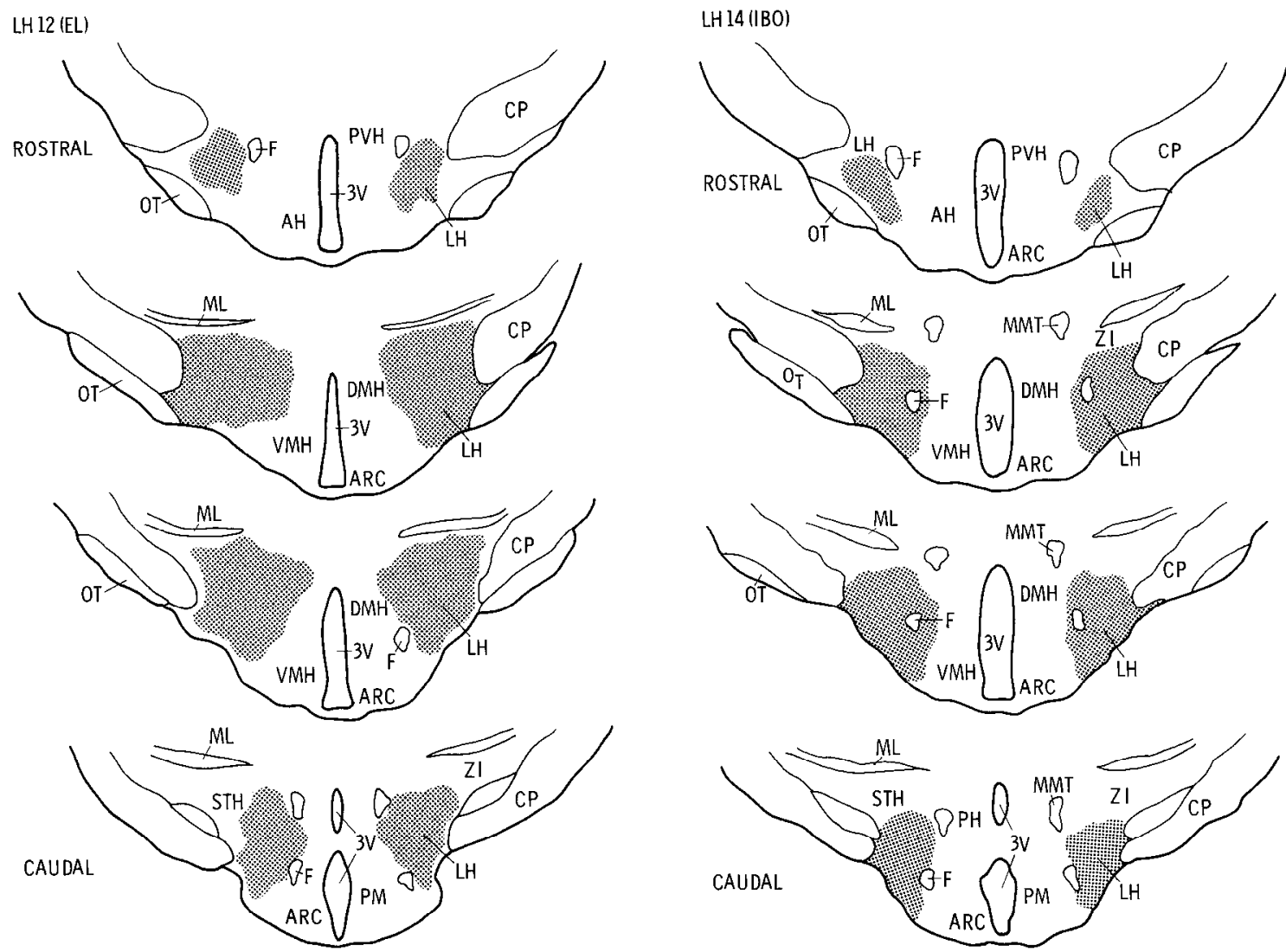

Figure 1. Lesions of the lateral hypothalamic area. LH 12 and LH 14 are typical cases with electrolytic $(E L)$ and ibotenic acid (IBO) lesions, respectively. Lesions, illustrated with stippling, tend to be bounded by the fornix medially and the cerebral peduncle laterally. $A H$, anterior hypothalamic nucleus; $A R C$, arcuate hypothalamic nucleus; $C P$, cerebral peduncle; $D M H$, dorsomedial hypothalamic nucleus; $F$, fornix; $M L$, medial lemniscus; $M M T$, mammilothalamic tract; $P M$, posteromedial hypothalamic nucleus; $O T$, optic tract; $S T H$, subthalamic nucleus; $V M H$, ventromedial hypothalamic nucleus; $Z I$, zona incerta; $3 V$, third ventricle.

the rats in the IBO group had unacceptable lesions and were eliminated from the data analysis.

The CS evoked increases in mean arterial pressure (MAP) in the control group (Fig. 3). In the animals with electrolytic or IBO lesions of LH, the change in arterial pressure was much smaller than in the control group (Fig. 3). A 2-way analysis of variance produced a significant $F$ statistic for the main effect of treatment $(F(2,32)=15.4, p<0.01)$, for the repeated measure $(F(9,288)=43.8, p<0.01)$, and for the interaction effect $(F(18,288)=4.3, p<0.01)$. Post hoc tests revealed that both the electrolytic and IBO groups were significantly different from the control group. The magnitude and pattern of the changes in MAP evoked by the CS in these rats with LH lesions were similar to those in rats with lesions of the dorsal amygdala (see Iwata et al., 1986b).

The data from the group with IBO lesions were reanalyzed using cumulative change in MAP as the measure (Fig. 4). In sham-operated controls, cumulative MAP increased steadily with each additional second of the CS. However, the rate of increase was much smaller in rats with IBO lesions of $\mathrm{LH}$. The changes in this group were, in fact, strikingly similar to those elicited in rats subjected to pseudoconditioning (random presentation of shock with respect to tone). The remaining changes in MAP evoked in LH-lesioned rats, therefore, may involve pathways controlling nonassociative, as opposed to associative, autonomic responses. Previous work suggests that these pathways diverge from the auditory projection system below the inferior colliculus (LeDoux et al., 1984).
In contrast to the effects of the lesions on the MAP changes, animals in the control and the 2 lesioned groups exhibited freezing throughout most of the CS (Fig. 3). The $F$ statistic for the 1-way analysis of variance was not significant $(F(2,30)=1.3$, n.s.). Two of the animals with electrolytic lesions of $\mathrm{LH}$ were eliminated from the freezing data analysis because they did not move during the initial baseline period.

The unconditioned response evoked by the footshock stimulus in the control group consisted of a rapid elevation of MAP that was maximal $2 \mathrm{sec}$ following the stimulus and a second, slightly larger, increase that was maximal 7 or $8 \mathrm{sec}$ after the stimulus (Fig. 5). The magnitude of the unconditioned response was unaffected by IBO lesions of LH (Fig. 5). The analysis of variance produced an insignificant $F$ statistic for the treatment effect $(F(1,23)=1.37$, n.s.) and for the interaction effect $(F(9,207)-0.99$, n.s.). Thus, electrolytic and IBO lesions of LH interfere with MAP but not with freezing-conditioned emotional responses. In contrast, unconditioned changes in arterial pressure evoked by footshock are unaffected by IBO lesions of LH. These findings indicate that intrinsic neurons in the LH are critically involved in the control of conditioned changes in MAP, but that LH neurons are not involved in the control of conditioned freezing or in the control of changes in MAP evoked by activation of peripheral pain pathways.

\section{Midbrain central gray lesions}

Two experiments were performed using lesions of the CG region. In the first study, electrolytic $(n=11)$ and IBO $(n=12)$ 

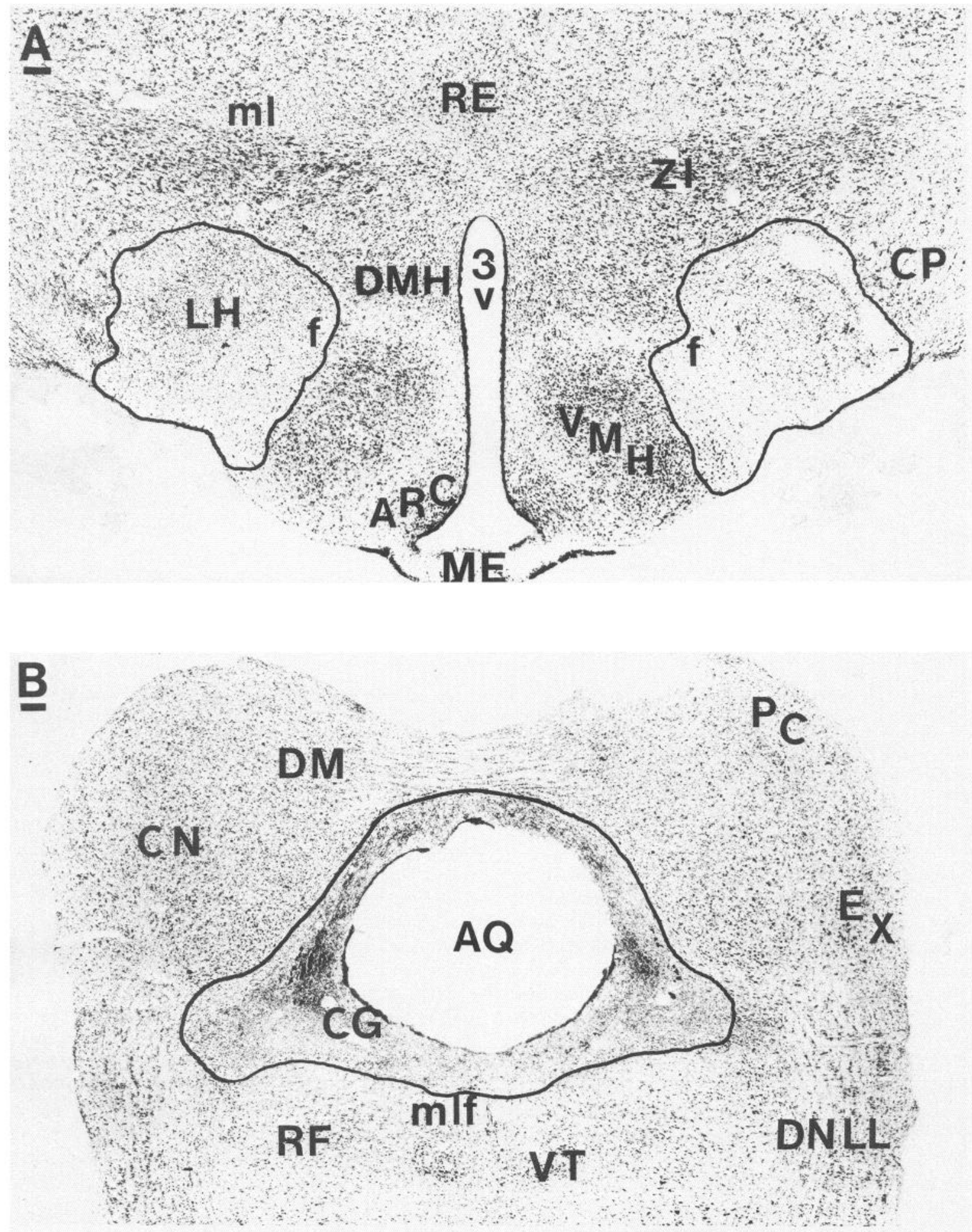

Figure 2. Photomicrographs illustrating the area of cell loss (enclosed by solid line) produced by injection of ibotenic acid into the lateral hypothalamic area $(A)$ and caudal aspects of the midbrain central gray region $(B)$. $A R C$, arcuate hypothalamic nucleus; $A Q$, cerebral aqueduct; $C G$, midbrain central gray region; $C N$, central nucleus of the inferior colliculus; $C P$, cerebral peduncle; $D M$, dorsomedial nucleus of the inferior colliculus; $D M H$, dorsomedial hypothalamic nucleus; $D N L L$, dorsal nucleus of the lateral lemniscus; $E X$, external nucleus of the inferior colliculus; $L H$, lateral hypothalamic area; $M E$, median eminence; $P C$, pericentral nucleus of the inferior colliculus; $R E$, reuniens thalamic nucleus; $R F$, reticular formation; $V M H$, ventromedial hypothalamic nucleus; $V T$, ventral tegmental area; $Z I$, zona incerta; $f$, fornix; $m l$, medial lemniscus; $m l f$, medial longitudinal fasciculus; $3 \mathrm{~V}$, third ventricle. 


\section{LATERAL HYPOTHALAMUS}
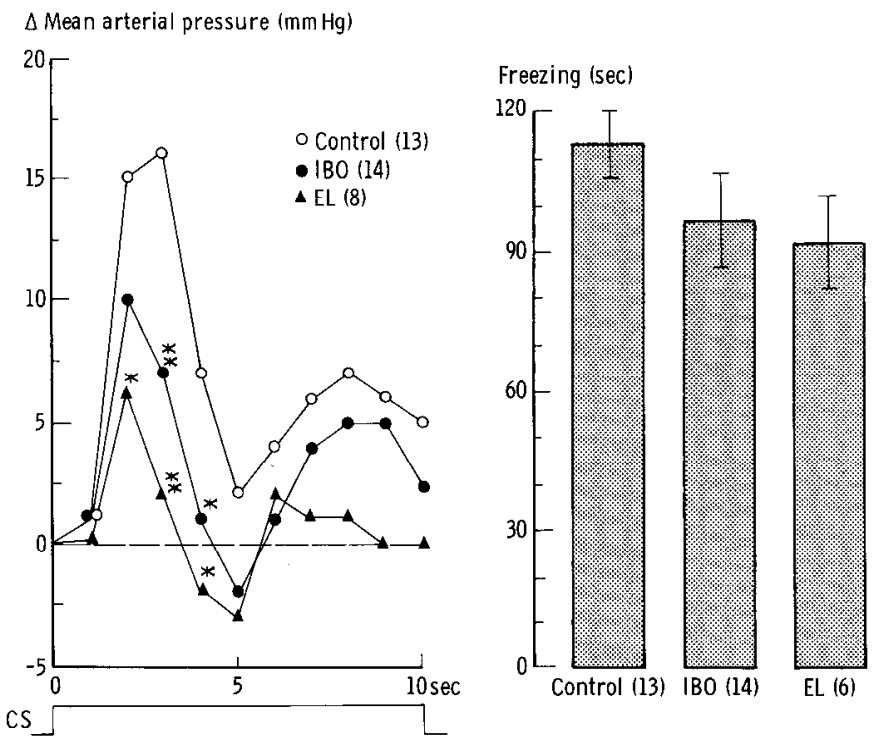

Figure 3. Interference with autonomic but not behavioral conditioned emotional responses by lesions of the lateral hypothalamic area. The magnitude of the arterial pressure-conditioned response was significantly reduced by electrolytic $(E L)$ and ibotenic acid $(I B O)$ lesions of the lateral hypothalamic area. In contrast, the freezing-conditioned response was unaffected. Thus, intrinsic neurons in the lateral hypothalamic area appear to be involved in the regulation of autonomic, but not behavioral, conditioned fear responses. The arterial pressure data represent grouped 3 trial averages of the second-by-second data recorded for each rat during extinction presentations of the $10 \mathrm{sec}$ conditioned stimulus $(C S)$. The freezing data represent the average amount of time rats in each group spent freezing during a 120 sec extinction presentation of the CS. Significance determined using analysis of variance and post hoc tests $\left({ }^{*} p<0.05 ;{ }^{* *} p<0.01\right)$.

lesions were made in the rostral CG area. These were compared to an unoperated control group $(n=9)$. Typical lesions are illustrated in Figure 6 . The electrolytic lesions tended to extend beyond the limits of the $\mathrm{CG}$ area and involved the midbrain

\section{$\triangle$ Mean arterial pressure $(\mathrm{mm} \mathrm{Hg})$}

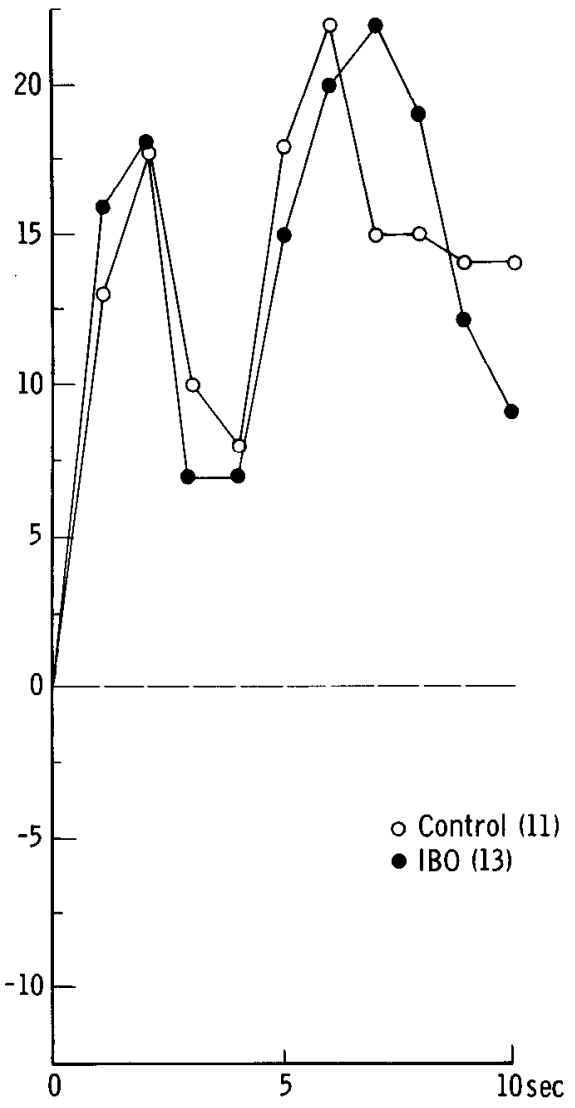

Figure 5. Fffects of lesions of the LH on unconditioned changes in arterial pressure evoked by footshock. IBO lesions had no effect on unconditioned responses. Data shown represent group averages of second-by-second data recorded during the $10 \mathrm{scc}$ following a single presentation of footshock $(2.2 \mathrm{~mA}, 0.5 \mathrm{sec})$. Significance determined using analysis of variance.

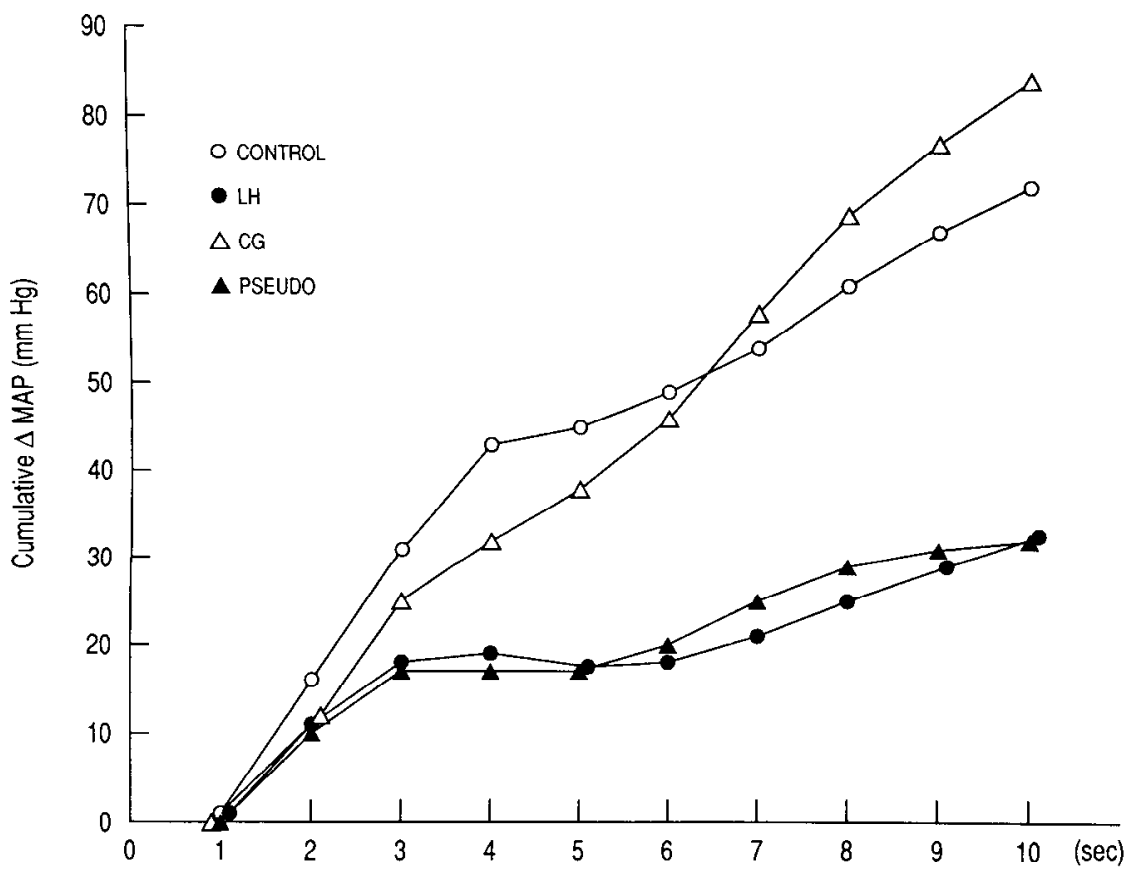

Figure 4. Cumulative change in mean arterial pressure $(M A P)$ evoked by the $\mathrm{CS}$. The MAP response recorded during cach sccond of a $10 \mathrm{sec}$ CS was added to the sum obtained for the previous seconds for each rat on each of the 3 trials. The cumulative 3 -trial average was averaged across rats in the different groups. IBO lesions of the lateral hypothalamic area $(L H)$ greatly reduced the cumulative change in MAP. The cumulative change in MAP in LH-lesioned animals was, in fact, similar to that evoked in rats given random presentation of the US with respect to the CS (PSEUDO). IBO lesions of the caudal central gray $(C G)$ had no effect on the cumulative change in MAP. 

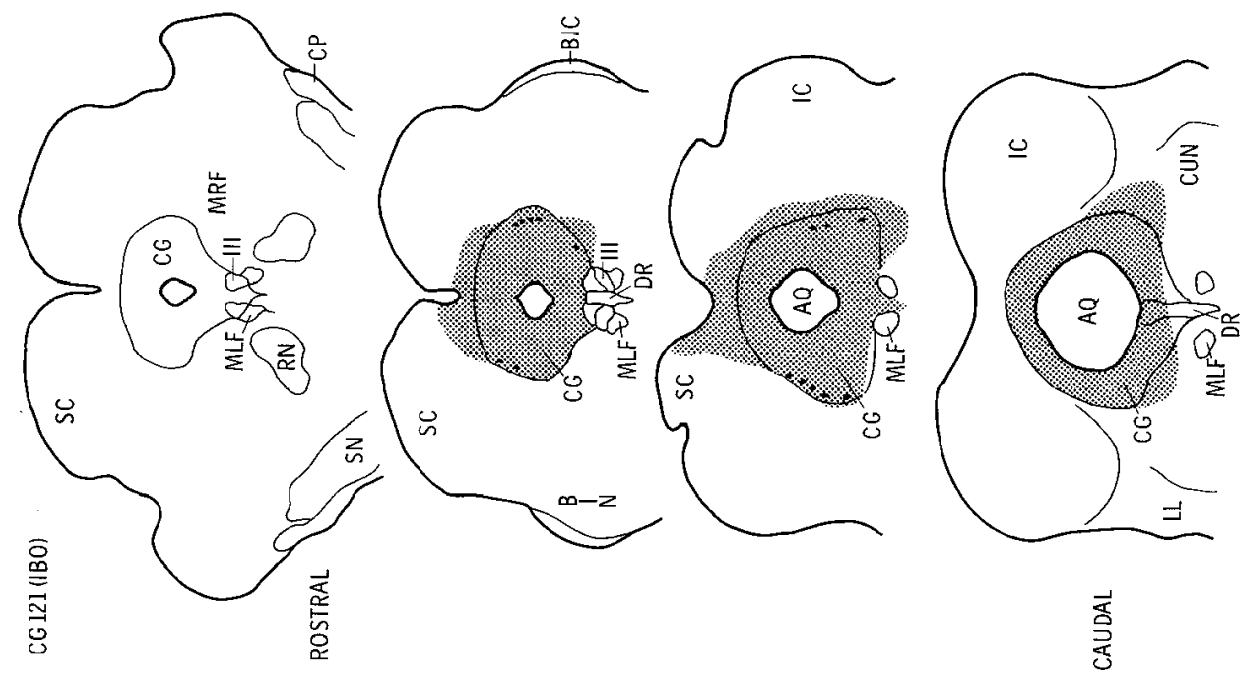

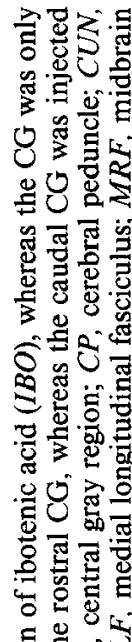

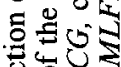

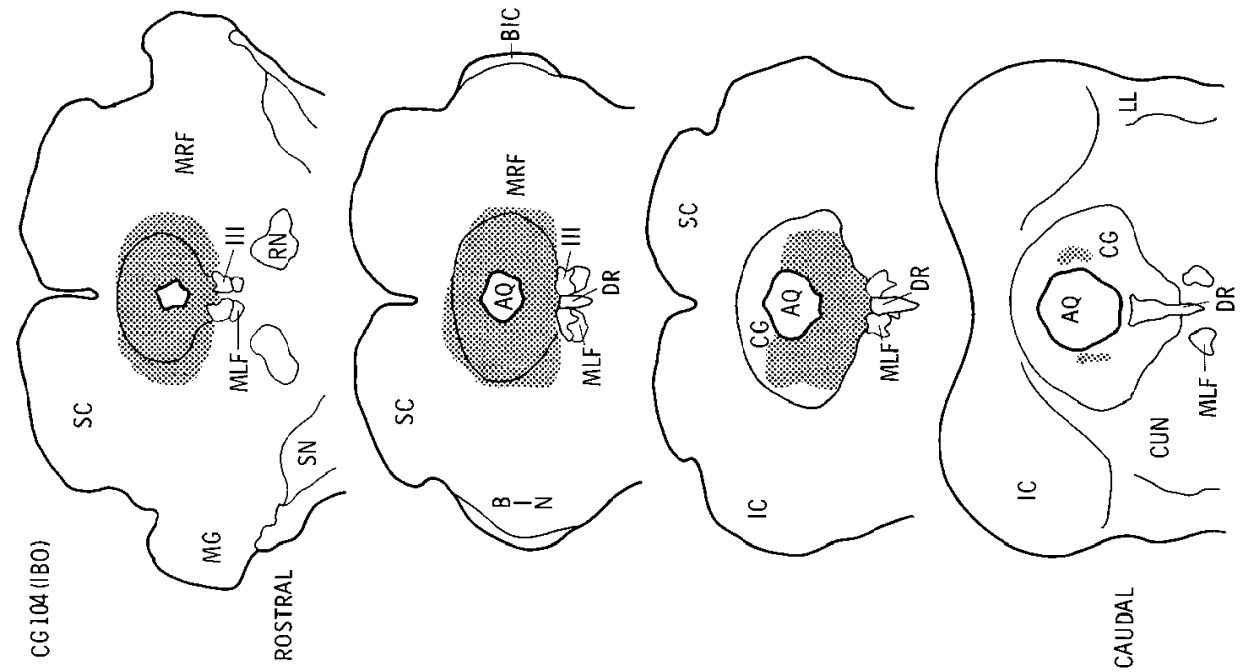

ن

两家

记

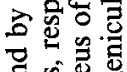

ह

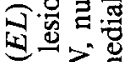

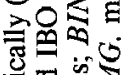

苋资

보을

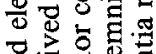

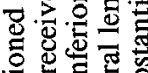

过吉焉

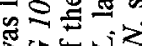

包式式

ॠ

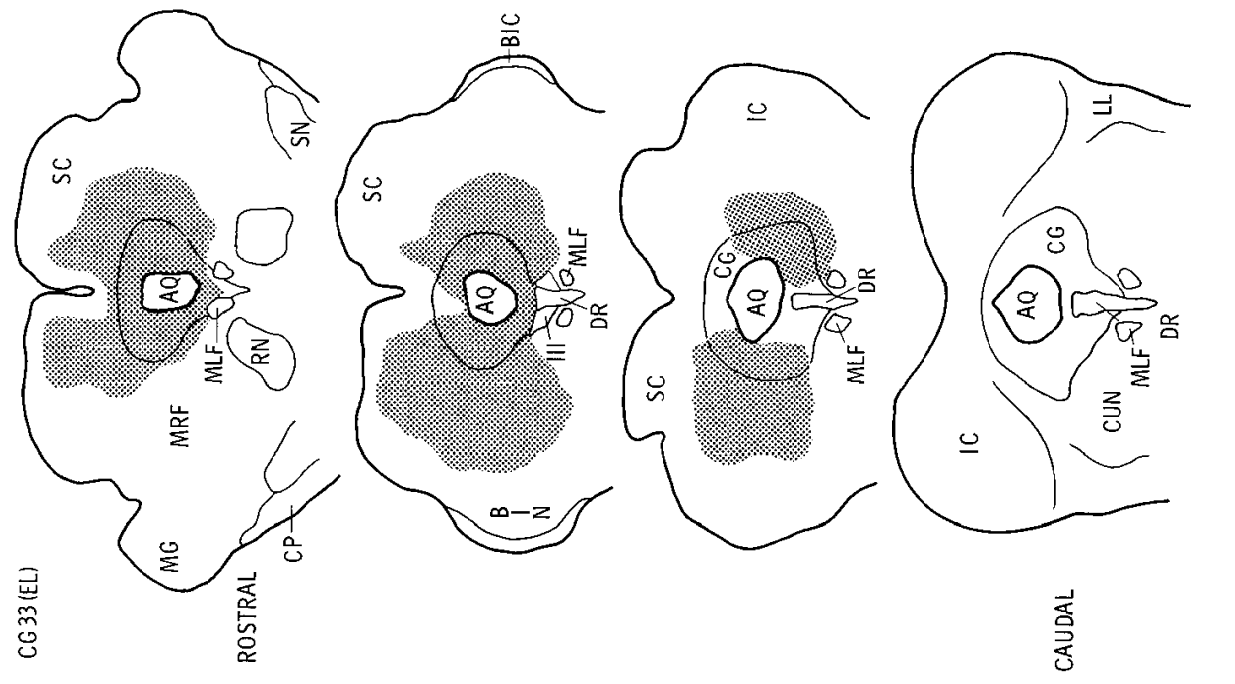

预的过总言

氙心记

कृ

F

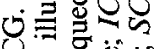

8 可

牙

ह

웡

tra

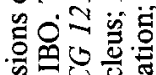

和的

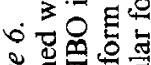

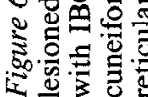


CENTRAL GRAY (ROSTRAL)
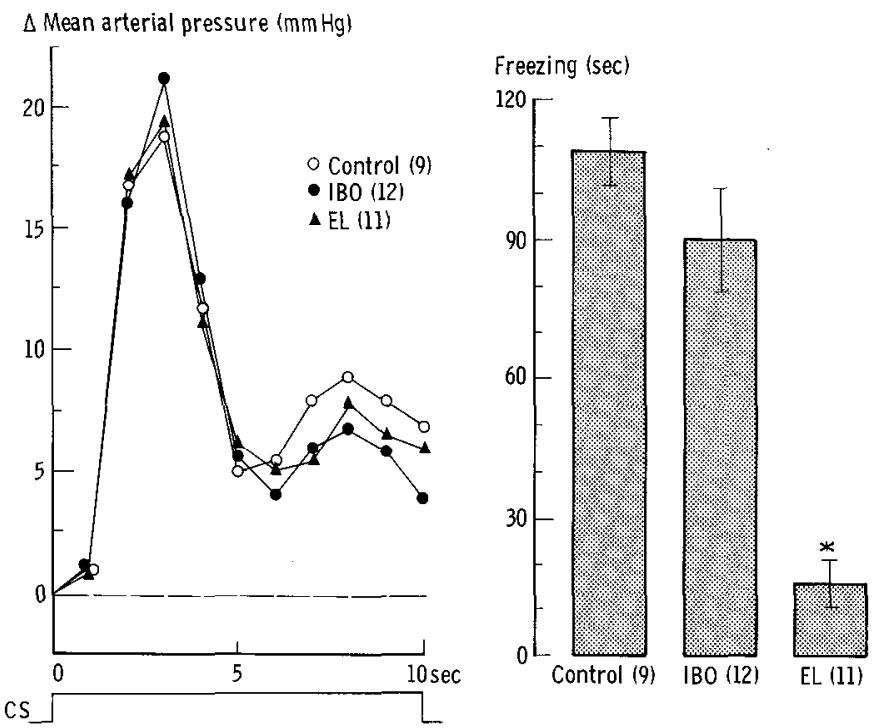

Figure 7. Electrolytic $(E L)$ lesions of the rostral CG disrupted the conditioned freezing response, but did not affect the arterial pressureconditioned response. In contrast, neither the freezing nor the arterial pressure responses were affected by IBO lesions of the rostral central gray. Thus, fibers passing through, but not synapsing in, the rostral CG appear to contribute to the expression of the freezing-conditioned response. The arterial pressure data represent grouped 3 trial averages of the second-by-second changes recorded for each animal during extinction presentations of the $10 \mathrm{sec}$ conditioned stimulus. The freezing data represent the average amount of time rats in each group spent freezing during a $120 \mathrm{sec}$ extinction presentation of the CS. Significance determined using analysis of variance and post hoc tests $\left({ }^{*} p<0.05\right)$.

reticular formation laterally and the superior colliculus dorsally. The IBO lesions, however, were largely confined to the CG and immediately adjacent areas.

Neither the electrolytic nor the IBO lesions of the rostral CG affected the conditioned MAP response (Fig. 7). The $F$ statistic from the analysis of variance was not significant for the main effect of treatment $(F(2,29)=0.77$, n.s. $)$ or for the interaction effect $(F(18,269)=0.77$, n.s. $)$. In contrast, the duration of freezing during the CS was greatly reduced in the electrolytic, but not the IBO, group (Fig. 7). The analysis of variance produced a significant treatment effect $(F(2,29)=20.1, p<0.01)$. Post hoc tests indicated that the significant $F$ test was accounted for by the difference between the electrolytic and the other 2 groups.

The failure of IBO lesions of the rostral CG to reproduce the effects of electrolytic lesions of the same area suggests that fibers passing through this area and terminating elsewhere mediate the freezing response. We thus examined whether IBO lesions of more caudal areas of CG would disrupt conditioned freezing. IBO was injected into the caudal CG in 15 rats. Six of these were eliminated after histological examination because of incomplete or inaccurate lesions. Vehicle was injected into the same area in 6 controls. A typical lesion is illustrated in Figures $2 b$ and 6.

As shown in Figure 8, IBO lesions of the caudal CG had no statistical effect on the MAP response (treatment effect: $F(1,12)$ $=0.14$, n.s.; interaction effect: $F(9,108)=1.3$, n.s.). Moreover, as shown in Figure 4, the cumulative increasc in MAP was
CENTRAL GRAY (CAUDAL)
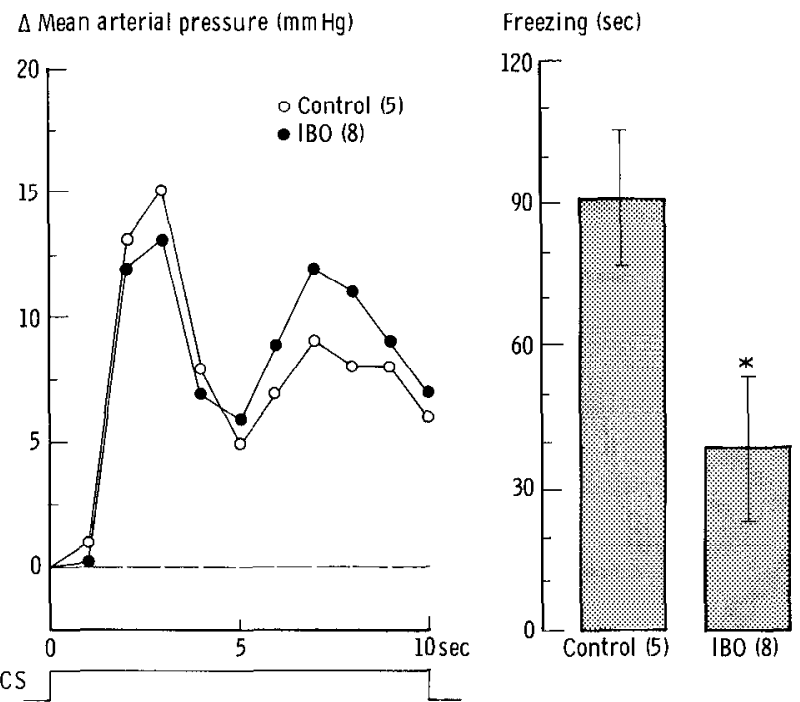

Figure 8. Injection of IBO into the caudal CG region significantly reduced the duration of conditioned freezing but did not affect the conditioned arterial pressure response. Thus, intrinsic neurons in the caudal CG contribute to the conditioned freezing, but not to the conditioned arterial pressure response. The arterial pressure data represent grouped 3 trial averages of the second-by-second changes recorded for each animal during extinction presentations of the $10 \mathrm{sec}$ conditioned stimulus. The freezing data represent the average amount of time rats in each group spent freezing during a $120 \mathrm{sec}$ extinction presentation of the CS. Significance determined using analysis of variance and post hoc tests $\left({ }^{*} p<0.05\right)$.

BED NUCLEUS OF STRIA TERMINALIS
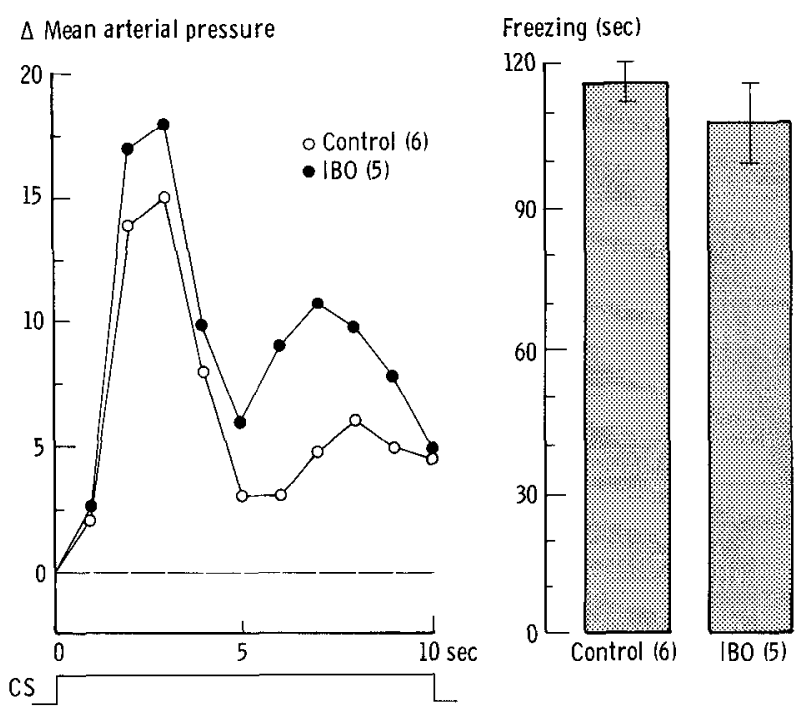

Figure 9. Destruction of intrinsic neurons in the bed nucleus of the stria terminals by injections of IBO had no effect on either the arterial pressure or the freezing-conditioned emotional responses. The arterial pressure data represent grouped 3 trial averages of the second-by-second changes recorded for each animal during extinction presentations of the $10 \mathrm{sec}$ conditioned stimulus. The freezing data represent the average amount of time rats in each group spent freezing during a $120 \mathrm{sec}$ extinction presentation of the CS. Significance evaluated using analysis of variancc. 


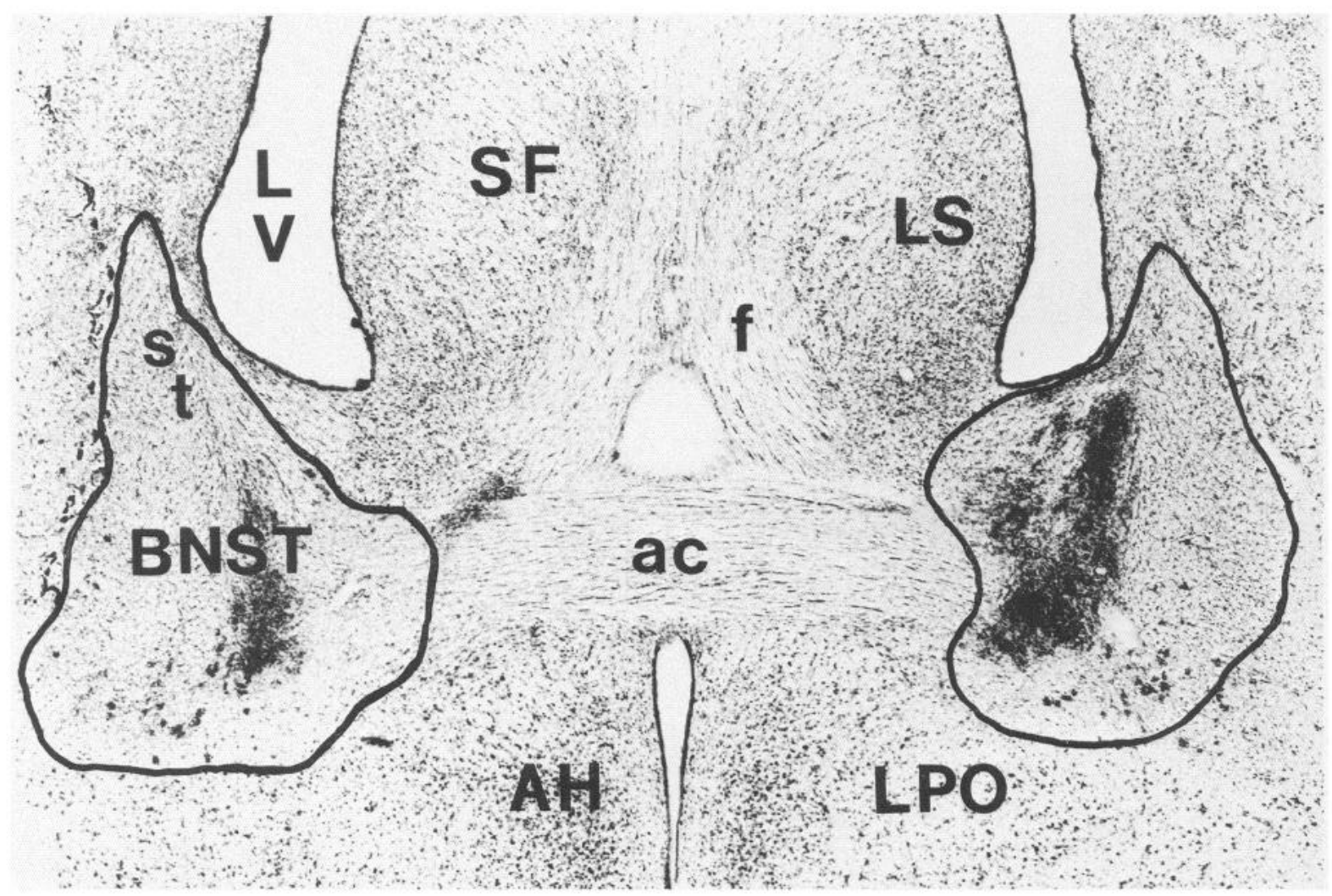

Figure 10. Photomicrograph illustrating the area of cell loss (enclosed by solid line) produced by microinjection of IBO into the bed nucleus of the stria terminals. $A H$, anterior hypothalamic nucleus; $B N S T$, bed nucleus of the stria terminals; $L P O$, lateral preoptic area; $L S$, lateral nucleus of the septum; $L V$, lateral ventricle; $S F$, septofimbrial nucleus; $a c$, anterior commissure; $f$, fornix; $s t$, stria terminalis.

similar in rats with IBO lesions of CG to that in controls. In contrast, freezing in response to the $\mathrm{CS}$ was significantly reduced by caudal CG lesions $(F(1,13)=5.8, p<0.05)$.

Thus, destruction of intrinsic neurons in the caudal, but not the rostral, CG interferes with the conditioned freezing response. Since the same lesions do not significantly reduce the conditioned MAP response, it would appear that intrinsic neurons in the caudal CG play a selective role in the control of somatomotor-conditioned responses and are not involved in the mediation of MAP-conditioned responses.

\section{Bed nucleus of the stria terminalis lesions}

IBO was injected into the BNST in 5 rats. Five controls received vehicle injections. A typical lesion is shown in Figure 9.

IBO lesions of BNST did not reduce the changes in MAP elicited by the CS (Fig. 10). The main effect of treatment $(F(1,8)=$ 1.5 , n.s. $)$ and the interaction effect $(F(9,72)=0.5$, n.s. $)$ were not significant. Similarly, the freezing response was unaffected $(F(1,8)$ $=1.4$, n.s.) by this lesion. BNST neurons thus do not appear to be part of either the MAP- or the freezing-conditioned response pathways.

\section{Discussion}

The purpose of the present study was to determine whether lesions of efferent projection targets of the ACE would disrupt the classical conditioning of changes in autonomic activity and/ or emotional behavior in the rat. The results demonstrate a double dissociation of lesion effects. Lesions of the LH interfere with autonomic, but not behavioral, conditioned responses, whereas lesions of the midbrain CG region interfere with behavioral, but not autonomic, conditioned responses. Since lesions of the amygdala or earlier stations (i.e., auditory thalamus or inferior colliculus) in the fear-conditioning pathway disrupt both behavioral and autonomic responses (LeDoux et al., 1984, 1986a, b; Iwata et al., 1986a), these findings suggest that the pathways mediating autonomic and behavioral conditioned fear responses diverge after the amygdala, with projections to the LH mediating autonomic changes and projections to the CG mediating behavioral changes.

\section{Amygdalo-hypothalamic autonomic conditioned fear-response pathway}

The viability of our hypothesis that classically conditioned changes in arterial pressure are mediated by projections from the ACE to the LH obviously depends on the existence of neural pathways connecting the central amygdala to the $\mathrm{LH}$, as well as of pathways connecting the $\mathrm{LH}$ with premotor neurons of the autonomic nervous system. Studies of several species, including rat, suggest that the LH receives projections from the ACE (Krettek and Price, 1978a; Shiosaka et al., 1980; Price and Amaral, 1981). However, these projections have not been universally observed in the rat (Kita and Oomura, 1982; Watson et al., 1983; Cassell et al., 1986). This discrepancy is most likely due to differences in location of injection sites. The central amygdala also projects to the LH by way of the caudal substantia innominata (Krettek and Price, 1978; Watson et al., 1983), which is viewed by some as a rostral extension of the central nucleus (de Olmos et al., 1985). LH neurons, in turn, are known to 
project to a variety of brain stem autonomic centers, including the rostral ventrolateral medulla, the dorsal motor nucleus of the vagus, and the nucleus of the solitary tract (Ross et al., 1981; Schwanzel-Fukuda et al., 1984; van der Kooy et al., 1984), as well as to cells in the intermediolateral column of the spinal cord (Saper et al., 1976; Tucker and Saper, 1985). Thus, the afferent and efferent connections of the LH are consistent with this structure's playing a crucial role in the mediation of cardiovascular-conditioned responses originating in the amygdala and structures afferent to the amygdala.

Our findings with lesions of LH confirm and extend the earlier work of Smith and associates (1980). In studies of primates, they demonstrated that electrolytic lesions of the LH disrupted the expression of autonomic, but not behavioral, conditioned emotional responses and, further, that these lesions left undisturbed the expression of autonomic changes associated with other behaviors, such as feeding and exercise. These observations suggest that the LH plays a crucial role in the expression of autonomic changes specifically associated with aversive emotional arousal. However, several major fiber bundles, including the fornix and the medial forebrain bundle, traverse in or near the LH. It is thus uncertain whether the effects of electrolytic lesions of $\mathrm{LH}$ are due to damage to neurons intrinsic to the $\mathrm{LH}$ or to the destruction of fibers originating elsewhere and passing through the LH. However, the results of the present study demonstrate that destruction of intrinsic neurons in LH by microinjection of IBO, which spares axons of passage, selectively disrupts MAP-conditioned responses, leaving behavioralconditioned responses undisturbed. Since the conditioned pressor response in the rat (Sakaguchi et al., 1983) and in primates (Smith et al., 1980 ) is mediated by the sympathetic division of the autonomic nervous system, these findings suggest that the lateral hypothalamic area is a synaptic way station for classically conditioned cardiovascular responses expressed through the peripheral sympathetic nerves.

It is not known whether classically conditioned autonomic responses expressed through parasympathetic channels also critically depend upon the integrity of neurons in the LH. Kapp et al. (1984), noting direct projections from the central amygdala to brain stem areas controlling the peripheral parasympathetic nerves, argue that these pathways might mediate the conditioned slowing of heart rate in the rabbit. However, neurons in the $\mathrm{LH}$ project to the same parasympathetic regions in the brain stem that receive direct inputs from the central amygdala (Ross et al., 1981; van der Kooy, 1984). Moreover, electrolytic lesions of the LH attenuate the conditioned bradycardia (Francis et al., 1981). However, since both fibers and local cell bodies are destroyed by the electrolytic lesions of $\mathrm{LH}$, the evidence available does not answer the question of whether LH neurons are a critical link between the central amygdala and the brain stem in the control of classically conditioned responses expressed through parasympathetic nerves.

It is of interest that destruction of neurons in the lateral hypothalamus failed to interfere with the expression of the cardiovascular response evoked by delivery of the footshock US in the present study. LH neurons are thus involved in controlling arterial responses evoked by stimuli symbolizing pain, but are not involved in the control of MAP responses evoked by direct activation of pain pathways. This observation is consistent with other findings suggesting that the somatosympathetic reflex evoked by painful stimuli is mediated by circuits below the midbrain (Sato and Schmidt, 1973).
We assume that LH lesions disrupted the arterial pressure response by breaking a link between the central amygdala and premotor neurons in the brain stem and spinal cord. Alternatively, LH lesions have been viewed as causing a disruption of conditioning by removing ascending inputs carrying reinforcement information to the forebrain (Francis et al., 1981).

Evidence against the reinforcement interpretation and in favor of the motoric interpretation of the effects of LH lesions on MAP conditioning is provided by our observation that sufficient reinforcement information reached the forebrain for behavioral responses to be conditioned. Further, since amygdala lesions interrupt both behavioral and MAP responses, while LH only disrupts MAP responses, we are led to the conclusion that $\mathrm{LH}$ is efferent to the amygdala for the autonomic response. Only by measuring multiple response modalities, each of which indexes fear conditioning, are we able to reach this conclusion. The use of unrelated response modalities provides much less information. For example, in some studies eye blink and heart rate responses are compared (e.g., Van Dercar and Schneiderman, 1967; Buchanan and Powell, 1980). However, since different central mechanisms underlie eye blink and heart rate conditioning (Thompson et al., 1983), the disruption of one response in the face of the survival of the other only distinguishes the 2 mechanisms. Such dissociations provide considerably less information about the pathways involved than do dissociations involving response modalities utilized by a common learning mechanism.

In summary, destruction of intrinsic neurons in LH disrupts the classical conditioning of changes in MAP. Neurons in $\mathrm{LH}$ are thus critically involved in the MAP-conditioned response pathway. However, since the conditioned freezing response survived both electrolytic and cellular lesions of $\mathrm{LH}$, neither neurons in $\mathrm{LH}$ nor fibers passing through $\mathrm{LH}$ are involved in the pathway mediating conditioned emotional behavior. Pathways projecting through, but not synapsing in, $\mathrm{LH}$ may modulate the unconditioned autonomic reaction to activation of pain pathways.

\section{Amygdala-central gray behavioral conditioned response pathway}

Our observation that electrolytic, but not IBO, lesions of the rostral CG disrupt behavioral and spare cardiovascular conditioned responses indicates that the fiber projection from the forebrain mediating the behavioral conditioned responses passes through, but does not synapse in, the rostral CG. Furthermore, our finding that IBO lesions of the caudal CG do interfere with the expression of conditioned fear behavior suggests that this caudal region is the destination of the fiber system projecting through the rostral CG.

Previous studies have implicated the CG in the expression of conditioned fear behavior (Lyon, 1964; Halpern, 1968; Liebman et al., 1970). Of particular interest is the study by Liebman et al. (1970). They found that electrolytic lesions of the ventral, but not dorsal, $\mathrm{CG}$ abolished conditioned fear reactions in the rat. These electrolytic lesions appear to have been located between the areas we define as the rostral and caudal levels of the $\mathrm{CG}$. This finding suggests that fibers en route to the caudal CG run through the ventral part of the more rostral areas of $C G$.

Several explanations of why CG lesions produce deficits in tests of conditioned fear behavior are reviewed by Liebman et al. (1970). Analgesia, they argue, is unlikely to account for the 
reduced signs of fear, since several studies show normal pain thresholds in CG-lesioned animals (Kelly and Glusman, 1968; Poirier et al., 1968). Liebman et al. also argue that the reduced fear behavior in CG-lesioned rats is not a by-product of hyperactivity, which CG-lesioned rats show, since other measures of fear, such as reduced defecation in an open field, also indicate a reduction in fearfulness. Liebman et al. (1970) conclude that the central substrate of fear itself is altered by CG lesions.

Our finding that conditioned cardiovascular responses survive $C G$ lesions supports Liebman et al.'s conclusion that altered sensitivity to pain is unlikely to explain the reduced fear response. The footshock stimulus was sufficiently aversive to sustain the conditioning of the arterial pressure response. However, the same finding challenges Liebman et al.'s (1970) conclusion that the central mechanism of fear is altered by $C G$ lesions. Presumably the MAP and freezing responses both reflect the conditioned state of fear. Any lesion that disrupts one but not the other response should be on the output side of the fear mechanism. By this reasoning, the central mechanism of fear is more likely to involve the amygdala than the CG. Efferent projections of the amygdala, such as the $\mathrm{CG}$ and $\mathrm{LH}$, might then be involved in the motoric expression of fear by linking the amygdala to appropriate motor systems.

CG has in fact been described as a component of a "midbrain locomotor region" (Swanson et al., 1984). The midbrain locomotor area receives projections from various limbic forebrain areas, including the central amygdala, and projects to spinal motor neurons. CG, seen in this light, may serve as an interface between the limbic forebrain and spinal cord in the expression of fear behavior. Lesions of the CG would, by this interpretation, disconnect spinal motor systems from the amygdala. Processes mediated by the amygdala would thus be deprived of access to final common pathways controlling emotional behavior when neurons in the caudal $\mathrm{CG}$ are destroyed.

\section{Contribution of other projections of the central amygdaloid nucleus}

In addition to $\mathrm{LH}$ and $\mathrm{CG}, \mathrm{ACE}$ projects to a number of other areas, including BNST, lateral nucleus of the substantia nigra, parabrachial region, nucleus reticularis pontis caudalis, nucleus of the solitary tract, dorsal motor nucleus of the vagus, rostral ventral lateral medulla, and spinal cord (e.g., Hopkins and Holstedge, 1978; Krettek and Price, 1978a; Saper, 1979; Price, 1981; Price and Amaral, 1981; Schwaber et al., 1982). Results in the present study demonstrate that IBO lesions of the BNST have no effect on either conditioned MAP or freezing responses. Little is known about the possible contribution, if any, of the other projections of ACE to the conditioned MAP and freezing responses.

\section{Relation of conditioned emotional response circuits to defense response pathways.}

Aversive classical conditioning is also described as defensive conditioning, reflecting the fact that the CS evokes a response pattern characteristic of the organism's species-typical reaction to threat. Defensive behaviors and accompanying autonomic changes can also be evoked by brain stimulation. In fact, the term, "defense reaction," was first used to describe the behavioral response evoked by electrical stimulation of the hypo- thalamus and other areas of the brain stem in the awake cat (Hess and Brügger, 1943). Since that time, many studies have been conducted using electrical brain stimulation to map the neural pathways mediating defensive behavior and the associated pattern of sympathetic activation (Abrahams et al., 1960; Hilton and Zbrozyna, 1963; Flynn, 1967; Kaada, 1967; Fonberg, 1972, 1973; Reis, 1972; Clemente and Chase, 1973; Hilton, 1975; Siegel and Edinger, 1981). It is assumed in such work that the neural pathways underlying defense reactions elicited by brain stimulation overlap considerably, if not completely, with the pathways through which defense is expressed in response to natural (sensory) stimuli. Results from the present study allow such comparisons to be made.

Studies using electrical stimuli to evoke defensive behaviors in awake animals have led to the conclusion that a pathway originating in the amygdala, projecting to the hypothalamus and, from there, to the $\mathrm{CG}$ is essential to the expression of these responses (see Kaada, 1967; Fonberg, 1972, 1973; Clemente and Chase, 1973; Siegel and Edinger, 1981). Particularly relevant are the results of Hunsperger (1956), showing that lesions of the hypothalmus or CG block the expression of defense responses evoked by amygdala stimulation.

Recent work by Bandler (1982; Bandler et al., 1985), however, questions whether neurons in the hypothalamus are indeed part of the defense circuit. He has shown that while electrical stimuli delivered to the medial hypothalamus evokes defense, stimulation of the same sites with excitatory amino acid fails to evoke the behavior. In contrast, both electrical and chemical stimulation of CG evokes defensive behavior. Since excitatory amino acids offer a way to selectively activate local neurons without concurrently exciting passing axons (Goodchild et al., 1982), these results suggest that neurons in the CG, but not the hypothalamus, are critical for the expression of behavioral defense responses. The same conclusion, interestingly, was reached in the present study of conditioned defensive behavior on the basis of IBO and electrolytic lesions of the hypothalamus. It should be noted, however, that our lesions were restricted to the lateral hypothalamus. A more detailed study of the effects of IBO lesions on various hypothalamic nuclei is needed to determine whether the lesion and stimulation results are in fact consistent with one another. However, with regard to the role of the $\mathrm{CG}$ in the control of emotional behavior, the lesion and stimulation data clearly do agree. We found that IBO lesions of the caudal, but not rostral, CG interfere with conditioned defensive behavior evoked by sensory stimuli, and Bandler et al. (1985) found that defense responses were more readily evoked from the caudal than from the rostral $\mathrm{CG}$ by microinjection of excitatory amino acids.

The autonomic component of the defense response has been studied mostly in anesthetized animals. Electrical stimulation in anesthetized animals of the areas from which defensive behavior is evoked in awake animals produces a pattern of sympathetic excitation characteristically evoked by threatening stimuli. Thus, electrical stimulation of sites in the amygdala, hypothalamus, and central gray evokes the cardiovascular defense pattern (Hilton and Zbrozyna, 1963; Hilton 1975; Yardley and Hilton, 1986). We recently found that microinjection of excitatory amino acids into the amygdala of freely behaving, conscious rats evokes increases in arterial pressure and heart rate, responses indicative of sympathetic excitation (Iwata et al., 1987). Delivery of excitatory amino acids to the hypothal- 
amus of anesthetized rats has given conflicting results. Sun and Guyenet (1987) recently reported that both electrical and chemical stimulation of the lateral hypothalamus increase systemic arterial pressure, increase lumbar sympathetic nerve discharge, and produce excitation in sympathetic premotor neurons in the rostral ventral lateral medulla. Further, they provide evidence that the pathway descending from LH is glutamatergic. Studies by Hilton's group, however, fail to find evidence for widespread sympathetic arousal, as in the cardiovascular defense response evoked by electrical stimulation of the hypothalamus, when hypothalamic neurons are excited with amino acids (Hilton and Redfern, 1986). Hilton and associates, however, find that sympathoexcitatory responses characteristic of the defense reaction are readily evoked from the $\mathrm{CG}$ by both electrical stimuli and excitatory amino acids (Hilton and Redfern, 1986; Yardley and Hilton, 1986). Differences in the anesthetic used, the depth of the anesthesia, or the sites stimulated might account for the discrepancy between the observations of Sun and Guyenet (1986) and Hilton and Redfern (1986).

Thus, studies using chemical stimuli to activate cardiovascular defense pathways suggest that the amygdala and probably the hypothalamus are important sites of integration. Moreover, the CG also appears to be an important link in this pathway. While the contribution of the amygdala and hypothalamus agrees with the lesion results reported here, the CG findings do not. Chemical lesions of $\mathrm{CG}$ failed to disrupt the cardiovascularconditioned responses. The discrepancy between the involvement of CG neurons in the regulation of cardiovascular defense responses produced by brain stimulation and that produced by sensory stimulation remains to be resolved. If this difference is supported by later work, the relevance of using direct stimulation of the brain as a model of the defense response evoked by natural stimuli would be open to question.

\section{Conclusion}

Results in the present study demonstrate that behavioral and autonomic conditioned emotional responses are separately disrupted by destruction of neurons in different areas projected to by the ACE. The findings are consistent with the hypothesis that the fear-conditioning pathway bifurcates in the amygdala, with projections from the central amygdala to the LH mediating conditioned autonomic responses, and projections from the central amygdala to the $\mathrm{CG}$ region mediating conditioned emotional behavior.

\section{References}

Abrahams, V. C., S. M. Hilton, and A. Zbrozyna (1960) Active muscle vasodilatation produced by stimulation of the brain stem: Its significance in the defence reaction. J. Physiol. (Lond.) 154: 491-513.

Amaral, D., and J. L. Price (1984) An air pressure system for the injection of tracer substances into the brain. J. Neurosci. Methods 9: $35-43$.

Applegate, C. D., R. C. Frysinger, B. S. Kapp, and M. Gallagher (1982) Multiple unit activity recorded from amygdala central nucleus during Pavlovian heart rate conditioning in rabbit. Brain Res. 238: 457-462.

Bandler, R. J. (1982) Induction of "rage" following microinjection of glutamate into midbrain but not hypothalamus of cats. Neurosci. Lett. 30: 183-188.

Bandler, R., S. Prineas, and T. McCulloch (1985) Further localization of midbrain neurons mediating the defence reaction in the cat by microinjections of excitatory amino acids. Neurosci. Lett. 56: 311316.
Bouton, M. E., and R. C. Bolles (1980) Conditioned fear assessed by freezing and by the suppression of three different baselines. Anim. Learn. Behav. 8: 429-434.

Buchanan, S. L., and D. A. Powell (1980) Divergencies in Pavlovian heart rate and eyeblink responses produced by hippocampectomy in the rabbit. Behav. Neural Biol. 30: 20-38.

Cassell, M. D., T. S. Gray, and J. Z. Kiss (1986) Neuronal architecture in the rat central nucleus of the amygdala: A cytological, histological and immunocytochemical study. J. Comp. Neurol. 246: 478-499.

Cicchetti, P., J. E. LeDoux, and D. J. Reis (1987) The lateral amygdaloid nuclcus: Sensory interface of the amygdala in fear conditioning. Soc. Neurosci. Abstr. 13: 643.

Clemente, C. D., and M. H. Chase (1973) Neurological substrates of aggressive behavior. Annu. Rev. Physiol. 35: 329-356.

Coyle, J. T., and R. Schwarcz (1983) The use of excitatory amino acids as selective neurotoxins. In Handbook of Chemical Neuroanatomy, vol. 1: Methods in Chemical Neuroanatomy, A. Björklund and T. Hökfelt, eds., Elsevier, Amsterdam.

de Olmos, J., G. F. Alheid, and C. A. Beltramino (1985) Amygdala. In The Rat Nervous System, I. Forebrain and Midbrain, G. Paxinos, ed., pp. 223-234, Academic, Sydney.

Flynn, J. P. (1967) The neural basis of agression in cats. In Biology and Behavior: Neurophysiology and Emotion, David C. Glass, ed., pp. 40-60, Rockefeller U. P. and Russell Sage Foundation, New York.

Fonberg, E. (1972) Control of emotional behavior through the hypothalamus and amygdaloid complex. In Physiology, Emotion, and Psychosomatic Illness, pp. 131-150, Ciba Foundation Symposium 8, Elsevier, Amsterdam.

Fonberg, E. (1973) The normalizing effect of lateral amygdalar lesions upon the dorsomedial amygdalar syndrome in dogs. Acta Neurobiol. Exp. 33: 449-466.

Francis, J., L. L. Hernandez, and D. A. Powell (1981) Lateral hypothalamic lesions: Effects on Pavlovian cardiac and eyeblink conditioning in the rabbit. Brain Res. Bull. 6: 155-163.

Galeno, T., and M. J. Brody (1983) Hemodynamic responses to amygdaloid stimulation in spontaneously hypertensive rats. Am. J. Physiol. 245: R281-R286.

Gentile, C. G., T. W. Jarrel, A. Teich, P. M. McCabe, and N. Schneiderman (1986) The role of amygdaloid central nucleus in the retention of differential Pavlovian conditioning of bradycardia in rabbits. Bchav. Brain Res. 20: 263-273.

Goodchild, A. K., R. A. L. Dampney, and R. J. Bandler (1982) A method for evoking physiological responses by stimulation of cell bodies, but not axons of passage within localized regions of the central nervous system. J. Neurosci. Methods 6: 351-363.

Halpern, M. (1968) Effects of midbrain central grey lesions on escapeavoidance behavior in rats. Physiol. Behav. 3: 171-178.

Heinemann, H., G. Stock, and H. Schaefer (1973) Temporal correlation of responses in blood pressure and motor reaction under electrical stimulation of limbic structures in unanesthetized, unrestrained cats. Pfluegers Arch. 343: 27-40.

Hess, W. R., and Brügger (1943) Das subkortikale Zentrum der afferktiven Abwehrreaktion. Helv. Physiol. Pharmacol. Acta (Basel) 1: $33-52$.

Hilton, S. M. (1975) Ways of viewing the central nervous control of the circulation-old and new. Brain Res. 87: 213-219.

Hilton, S. M., and W. S. Redfern (1986) A search for brain stem cell groups integrating the defence reaction in the rat. J. Physiol. (Lond.) 378: $213-228$.

Hilton, S. M., and A. W. Zbrozyna (1963) Amygdaloid region for defence reactions and its efferent pathway to the brain stem. J. Physiol. (Lond.) 165: 160-173.

Hitchcock, J. M., and M. Davis (1986) Amydgala lesions block fearenhanced startle using either visual or auditory conditioned stimuli. Soc. Neurosci. Abstr. 12: 752.

Hopkins, D. A., and G. Holstedge (1978) Amygdala projections to the mesencephalon, pons and medulla oblongata in the cat. Exp. Brain Res. 32: 529-547.

Hunsperger, R. W. (1956) Affektreaktionen auf elektrische Reizung im Hirnstamm der Katze. Helv. Physiol. Pharmacol. Acta (Basel) 14: 70-92.

Iwata, J., J. E. LeDoux, M. P. Meeley, S. Arneric, and D. J. Reis (1986a) Intrinsic neurons in the amygdaloid field projected to by the medial 
geniculate body mediate emotional responses conditioned to acoustic stimuli. Brain Res. 383: 195-214.

Iwata, J., J. E. LeDoux, and D. J. Reis (1986b) Destruction of intrinsic neurons in the lateral hypothalamus disrupts the classical conditioning of autonomic but not behavioral emotional responses in the rat. Brain Res. 368: 161-166.

Iwata, J., K. Chida, and J. E. LeDoux (1987) Cardiovascular responses elicited by stimulation of neurons in the central amygdaloid nucleus in awake but not anesthetized rats resemble conditioned emotional responses. Brain Res. 418: 183-187.

Kaada, B. R. (1967) Brain mechanisms related to aggressive behavior. In Aggression and Defense - Neural Mechanisms and Social Patterns, C. Clemente and D. B. Lindsley, eds., pp. 95-133, University of California Press, Berkeley, CA

Kapp, B. S., R. C. Frysinger, M. Gallagher, and J. Haselton (1979) Amygdala central nucleus lesions: Effects on heart rate conditioning in the rabbit. Physiol. Behav. 23: 1109-1117.

Kapp, B. S., M. Gallagher, M. Underwood, C. L. McNall, and D. Whitehorn (1982) Cardiovascular responses elicited by electrical stimulation of the amygdala central nucleus in the rabbit. Brain Res. 234 251-262.

Kapp, B. S., J. P. Pascoe, and M. A. Bixler (1984) The amygdala: A neuroanatomical systems approach to its contributions to aversive conditioning. In The Neuropsychology of Memory, N. Buttlers and L. R. Squire, eds., pp. 473-488, Guilford, New York.

Kelly, D. D., and M. Glusman (1968) Aversive thresholds following midbrain lesions. J. Comp. Physiol. Psychol. 66: 25-34.

Kita, H., and Y. Oomura (1982) An HRP study of the afferent connections to rat lateral hypothalamic region. Brain Res. Bull. 8: 6371 .

Krettek, J. E., and J. L. Price (1978a) Amygdaloid projections to subcortical structures within the basal forebrain and brainstem in the rat and cat. J. Comp. Neurol. 178: 225-253.

Krettek, J. E., and J. L. Price (1978b) A description of the amygdaloid complex in the rat and cat with observations on intra-amygdaloid axonal connections. J. Comp. Neurol. 178: 255-280.

LeDoux, J. E. (1986) Neurobiology of emotion. In Mind and Brain: Dialogues in Cognitive Neuroscience, J. E. LeDoux and W. Hirst, eds., pp. 301-354, Cambridge U. P., New York.

LeDoux, J. E. (1987) Emotion. In Handbook of Physiology: Nervous System V, F. Plum, ed., pp. 419-459, American Physiological Society, Washington, DC.

LeDoux, J. E., A. Del Bo, L. W. Tucker, G. Harshfield, W. T. Talman, and D. J. Reis (1982) Hierarchic organization of blood pressure responses during the expression of natural behaviors in rat: Mediation by sympathetic nerves. Exp. Neurol. 78: 121-133.

LeDoux, J. E., A. Sakaguchi, and D. J. Reis (1984) Subcortical efferent projections of the medial geniculate nucleus mediate emotional responses conditioned to acoustic stimuli. J. Neurosci. 4: 683-698.

LeDoux, J. E., D. A. Ruggiero, and D. J. Reis (1985) Projections to the subcortical forebrain from anatomically defined areas of the rat medial geniculate body. J. Comp. Neurol. 242: 182-213.

LeDoux, J. F., J. Iwata, D. Pearl, and D. J. Reis (1986a) Disruption of auditory but not visual learning by destruction of intrinsic neurons in the rat medial geniculate body. Brain Res. 371: 395-399.

LeDoux, J. E., A. Sakaguchi, J. Iwata, and D. J. Rcis (1986b) Interruption of projections from the medial geniculate body to an archineostriatal field disrupts the classical conditioning of emotional responses to acoustic stimuli. Neuroscience 17: 615-627.

Liebman, J. M., D. J. Mayer, and J. C. Liebeskin (1970) Mesencephalic central gray lesions and fear-motivated behavior in rats. Brain Res. 23: $353-370$.

Lyon, M. (1964) The role of central midbrain structures in conditioned responding to aversive noise in the rat. J. Comp. Neurol. 122: 407429.

Pascoe, J., and B. B. Kapp (1985a) Electrophysiological characteristics of amygdaloid central nucleus neurons in the awake rabbit. Brain Res. Bull. 14: 331-338.

Pascoe, J. P., and B. S. Kapp (1985b) Electrophysiological characteristics of amygdaloid central nucleus neurons during Pavlovian fcar conditioning in the rabbit. Behav. Brain Res. 16: 117-133.

Paxinos, G., and C. Watson (1982) The Rat Brain in Stereotaxic Courdinales, Academic, New York.

Poirier, L. J., G. Bouvier, A. Oliver, and R. Boucher (1968) Cerebro- cortical structures related to pain. In Pain, A. Soulairac, J. Chan, and J. Charpentier, eds., pp. 33-42, Academic, New York.

Price, J. L. (1981) The efferent projections of the amygdaloid complex in the rat, cat and monkey. In The Amygdaloid Complex, Y. BenAri, ed., pp. 121-132, Inserm Symposium 20, Elsevier, Amsterdam.

Price, J. L., and D. G. Amaral (1981) An autoradiographic study of the projections of the central nucleus of the monkey amygdala. $\mathbf{J}$. Neurosci. 1: 1242-1259.

Reis, D. J. (1972) The relation between brain norepinephrine and aggressive behavior. Res. Publ. Assoc. Res. Nerv. Ment. Dis. 50: 266-296.

Reis, D. J., and M. C. Oliphant (1964) Bradycardia and tachycardia following electrical stimulation of the amygdaloid region in the monkey. J. Neurophysiol. 27: 893-912.

Ross, C. A., D. A. Armstrong, D. A. Ruggiero, V. M. Pickel, T. H. Joh, and D. J. Reis (1981) Adrenaline neurons in the rostral ventrolateral medulla innervate thoracic spinal cord: A combined immunocytochemical and retrograde transport demonstration. Neurosci. Lett. 25 . 257-262.

Sakaguchi, A., J. E. LeDoux, and D. J. Reis (1983) Sympathetic nerves and adrenal medulla. Contributions to cardiovascular-conditioned emotional responses in spontaneously hypertensive rats. Hypertension 5: 728-738.

Saper, C. B. (1979) Anatomical substrates for the hypothalamic control of the autonomic nervous system. In Integrative Functions of the Autonomic Nervous System, C. McBrooks, K. Loizumi, and A. Sato, eds., pp. 333-341, U. Tokyo Press, Tokyo.

Saper, C. B., A. D. Loewy, L. W. Swanson, and W. M. Cowan (1976) Direct hypothalamo-autonomic projections. Brain Res. 117: 305312.

Sato, A., and Schmidt, R. F. (1973) Somatosympathetic reflexes: Afferent fibers, central pathwáys, discharge characteristics. Physiol. Rev. 53: 916-942.

Schwaber, J. S., B. S. Kapp, G. A. Higgins, and P. R. Rapp (1982) Amygdaloid and basal forebrain direct connections with the nucleus of the solitary tract and the dorsal motor nucleus. I. Neurosci. 2: $1424-1438$.

Schwanzel-Fukuda, M., J. I. Morrel, and D. W. Pfaff (1984) Localization of forebrain neurons which project directly to the medulla and spinal cord of the rat by retrograde tracing with wheat germ agglutinin. J. Comp. Neurol. 226: 1-20.

Shiosaka, S., M. Tokyama, H. Takagi, Y. Takahashi, Y. Saitoh, T. Sakumoto, H. Nakagawa, and N. Shimizu (1980) Ascending and descending components of the medial forebrain bundle in the rat as demonstrated by the horseradish peroxidase-blue reaction. I. Forebrain and upper brainstem. Exp. Brain Res. 39: 377-388.

Siegel, A., and H. Edinger (1981) Neural control of aggression and rage behavior. In Handbook of the Hypothalamus, vol. 3: Behavioral Studies of the Hypothalamus, P.J. Morgane and J. Panksepp, eds., pp. 203-240, Dekker, New York.

Smith, O. A., C. A. Astley, J. L. DeVito, J. M. Stein, and R. E. Walsh (1980) Functional analysis of hypothalamic control of the cardiovascular responses accompanying emotional behavior. Fed. Proc. 29. $2487-2494$.

Snyder, D. W., M. A. Nathan, and D. J. Reis (1978) Chronic lability of arterial pressure produced by selective destruction of the catecholamine innervation of the nucleus tractus solitarii in rat. Circ. Res. 43: $662-671$.

Sun, M-K., and P. G. Guyenet (1986) Hypothalamic glutamatergic input to medullary sympathoexcitatory neurons in rat. Am. J. Physiol. 251: 798-810.

Swanson, L. W., G. J. Mogenson, C. R. Gerfen, and P. Robinson (1984) Evidence for a projection from the lateral preoptic area and substantia innominata to the "mesencephalic locomotor region" in the rat. Brain Res. 295: 161-178.

Thompson R. F., T. W. Berger, and J. Madden IV (1983) Cellular processes of learning and memory in the mammalian CNS. Annu. Rev. Neurosci. 6: 447-491.

Tucker, D. C., and C. B. Saper (1985) Specificity of spinal projections from hypothalamic and brainstem areas which innervate sympathetic preganglionic neurons. Brain Res. 360: 159-164.

Ursin, H., and B. R. Kaada (1960) Functional localization within the amygdaloid complex in the cat. EEG Clin. Neurophysiol. 12: 1-20.

Van Dercar, D. H., and N. Schneiderman (1967) Interstimulus interval 
functions in different response systems during classical discrimination conditioning of rabbits. Psychonom. Sci. 9: 9-10.

van der Kooy, D., L. Y. Koda, J. F. McGinty, C. R. Gerfen, and F. E. Bloom (1984) The organization of projections from the cortex, amygdala, and hypothalamus to the nucleus of the solitary tract in rat. J. Comp. Neurol. 224: 1-24.

Watson, R. E., R. Troianio, J. Pualakos, S. Weiner, S. Block, and A.
Siegel (1983) $\mathrm{A}{ }^{14} \mathrm{C} 2$-deoxyglucose analysis of the functional neural pathways of the limbic forebrain in the rat. I. The amygdala. Brain Res. Rev. 5: 1-44.

Yardley, C. P., and S. M. Hilton (1986) The hypothalamic and brainstem areas from which the cardiovascular and behavioral components of the defence reaction are elicited in the rat. J. Autonom. Nerv. Syst. 15: $227-244$ 